\title{
Marivaux contra la tiranía: la utopía igualitaria de L'île des esclaves
}

\author{
Marivaux against tyranny: L'île des \\ esclaves as an egalitarian utopia
}

\author{
Juan Manuel Ibeas-Altamira \\ Universidad del País Vasco (UPV/EHU) \\ juan.ibeas@ehu.eus
}

\begin{abstract}
In this article we propose the study of Pierre Carlet de Chamblain de Marivaux's "L'île des esclaves" (1725). This French novelist and dramatist wrote numerous comedies analyzing the stages of love and the fragility of feelings and amorous desire; but a further study shows a "revolutionary" ideology. In this retro-chronotope Marivaux attacks slavery and invites us to consider the ethics of our choices and actions. If today slavery is one of the things that everyone agrees is unethical, in the eighteenth century this trade made up about de half of Europe's income, and Marivaux's arguments were not so easy to accept.
\end{abstract}

\section{Key-words}

Eighteenth century, theater, Marivaux, slavery

\begin{abstract}
Résumé
Cet article propose une étude de "L'île des esclaves" de Pierre Carlet de Chamblain de Marivaux (1725). Ce romancier et dramaturge analysa dans ses œuvres les progrès de l'amour et la fragilité des sentiments et de la passion amoureuse; mais une étude approfondie nous révèle son idéologie "révolutionnaire". Dans cette retro-chronotopie Marivaux s'attaque à l'esclavage et nous invite à réfléchir sur l'éthique de nos choix et de nos actions. Si de nos jours le caractère immoral de l'esclavage fait l'unanimité, au XVIII ${ }^{\mathrm{e}}$ siècle les arguments de Marivaux n'étaient pas faciles à accepter, puisque la moitié des richesses de l'Europe avaient leur origine dans la traite négrière.
\end{abstract}

\section{Mots-clés}

XVIIIe siècle, Théâtre, Marivaux, esclavage 


\section{Introducción}

\subsection{Orígenes y estudios de la esclavitud}

La esclavitud se encuentra en el origen de la humanidad, aunque no se dé en todas las civilizaciones. Se remonta a la Prehistoria, aunque se asienta y regula en la Edad Antigua, cuando las primeras civilizaciones aprovechan como mano de obra a los cautivos en las guerras y a los habitantes de los pueblos conquistados, como alternativa a otra posibilidad también frecuente: sacrificarlos a los dioses. Así hoy sabemos que el florecimiento cultural y económico de la Atenas de Pericles o de la Roma clásica se basaba en una economía soportada por la fuerza de trabajo esclava (Kleff, 2006).

En los textos de los autores griegos antiguos como Aristóteles, la esclavitud se considera como un fenómeno natural e inherente a la vida en sociedad. Incluso en sus escritos utópicos los griegos no llegan a plantearse la desaparición de esta forma social (Garnsey, 1996: 15). Platón en su diálogo Las Leyes (en griego, Nórol) y Aritófanes en su comedia Las Aves (en griego $O \rho v \imath \varepsilon \varsigma$, Ornithes, una alegre utopía político-religiosa) los incluyen sin duda alguna ${ }^{1}$. Ni siquiera se cuestiona en ningún momento la esclavitud en las "ciudades invertidas" (como en las comedias de Artistófanes Lisistrata y La Asamblea de las mujeres) donde se invierten los roles entre hombres y mujeres, o entre la propiedad privada y la pública: los esclavos nunca cambian su papel por el de los amos. Únicamente desaparecen, pero por completo, en las representaciones helenas de la Edad de Oro o en las de los países de Cucaña como en la obra Anfictiones de Teleclides, pero es porque la masa del pan se amasa sola y la bebida se sirve sola.

Los romanos mantienen la herencia griega al respecto con muy pocas variantes (Wallon, 1988), y con el paso al feudalismo la esclavitud no desaparece por completo (Verlinden, 1955) y aunque en ocasiones parezca marginal, perdura hasta la Edad Moderna, volviéndose fundamental, como sabemos, durante la colonización de América. De manera que podemos decir que (exceptuando algunas emancipaciones de esclavos puntuales o proclamas de liberación de ciertas regiones) hasta avanzado el siglo XVIII no hay un cuestionamiento real de la esclavitud ni aparece un verdadero movimiento antiesclavista. Es en este siglo cuando se produce verdaderamente la toma de conciencia de la inadmisibilidad económica, política y moral del sistema colonial esclavista (Ehrard, 2008).

\subsection{Las 'Luces'y la esclavitud}

La cuestión de la rentabilidad de este sistema económico se plantea con la aparición de la economía preclásica y la clásica: los fisiócratas franceses (Dupont de Nemours, Mira-

1 En la República platónica la esclavitud no aparece de manera explícita, los críticos difieren a la hora de fijar la opinión del filósofo sobre su necesidad en su estructura política (Pellegrin, 1982: 350). A favor de su existencia tenemos la obra de Vlastos (1968: 291-295) y en contra la de Calvert (1987: 367-372). 
beau, Turgot, Condorcet) junto con Adam Smith y otros economistas ingleses, argumentando la superioridad del trabajo libre, cuestionan el valor económico del trabajo del esclavo y aseguran que en realidad éste supone un freno para el desarrollo del mercado interior. Por otro lado, consideran que la producción se ve acrecentada por el interés del trabajador libre por su trabajo y por la ausencia de coste de compra y mantenimiento. Además, todo ello se ve favorecido considerablemente por un menor índice de riesgo: no hay revueltas ni motines, ni necesidad de vigilantes. Solo algunas voces esclavistas se atreverán a defender entonces que la riqueza de las naciones y su prosperidad correrían un serio riesgo; al fin y al cabo no podemos olvidar que la trata de negros en los siglos XVII y XVIII está ligada al desarrollo de las grandes compañías comerciales y a la expansión colonial de los países europeos hacia el Nuevo Mundo, y muchas de las grandes fortunas de la época (incluso la de muchos enciclopedistas e ilustrados) se basan en el famoso comercio triangular (Chesnais, 2000).

Del mismo modo estos cuestionamientos económicos se ven reforzados como sabemos por todo un cuestionamiento moral y filosófico por parte de los grandes hombres de las Luces francesas: Montesquieu, Voltaire, Rousseau, Diderot, Raynal. Desde mediados del siglo XVIII el tema aparece a menudo en los escritos de estos y otros autores e incluso se incluye en la Enciclopedia de Diderot y D'Alembert, donde el caballero de Jaucourt (de origen protestante, no lo olvidemos) condenaba la esclavitud en un artículo titulado "trata de negros" asegurando que era un negocio que violaba la religión, la moral, las leyes naturales y los derechos de la naturaleza humana (Jaucourt, 1751-1772). Por supuesto recibieron ataques por parte del mundo católico y por parte de los anticolonialistas pero su mensaje fue calando hasta materializarse en el decreto de la Convención del 16 de pluvioso del año II (4 de febrero de 1794), un decreto que no obstante se limita a la Guadalupe y que no incluye ni la isla Mauricio ni la Reunión ni por supuesto la Martinica que entonces estaba en posesión de los ingleses ${ }^{2}$. Por lo tanto, hemos de tener presente que pese a que en ocasiones los autores de las Luces puedan parecernos suaves o ambiguos en sus condenas la elaboración de la cultura crítica antiesclavista rompe una tradición de legitimación teórica de la esclavitud muy antigua y asentada y que por eso es un trabajo gradual dentro del discurso civilizador, universalista y cosmopolita del XVIII. Si las técnicas empleadas son poco claras o si recurren a géneros de apariencia poco seria es porque deben enfrentarse a un público en principio muy opuesto y el cambio ha de ser muy paulatino.

2 En junio de 1820 Joseph-Elzéar Morenas presenta en la Cámara de diputados una solicitud para acabar con la trata de negros que se sigue practicando en Senegal, pero hasta la revolución de 1848 y la abdicación de Luis Felipe, no se toman medidas concretas. El 27 de abril de 1848 el gobierno provisional abole la esclavitud en todas las colonias (en Martinica el 23 de mayo, en Guadalupe el 27, en Guayana el 10 de agosto y en la Reunión el 20 de diciembre). Esta derogación se recoge en el artículo número 6 de la constitución del 4 de noviembre de 1848. El comercio ilegal perduró un poco más; pronto se reemplazó a los esclavos por trabajadores orientales, los conocidos como 'culíes' o 'coolies' (Schmidt, 2008). 


\subsection{Marivaux y la rueda de la Fortuna}

En esta línea surgen como sabemos numerosos textos que permiten a la sociedad francesa reflexionar sobre esa realidad social ya por su contenido crítico (como las celebérrimas Lettres persanes de 1721, el Esprit des Lois $^{3}$ de 1748 o Candide de 1759), ya por su descripción de la realidad de ultramar como los textos de los misioneros (Jean-Baptiste Du Tertre o Jean-Baptiste Labat), de los funcionarios de las colonias (Pierre Poivre o Bernardin de Saint-Pierre), de autores de la metrópoli como el ya analizado Saint-Lambert (y su Ziméo, 1769) o Jean Castilhon (Zingha, reine d'Angola, histoire africaine, 1770) o incluso los versos de los poetas criollos como Évariste de Parny, Antoine de Bertin o Nicolas-Germain Léonard. Además, en todas estas obras el elemento paratextual (suplementos, paratextos, ilustraciones y demás) ilustran de un modo aún más incisivo la brutalidad de la condición servil y de la opresión al esclavo.

Si se presta atención a las fechas de publicación de estas obras, en general, responden a una clara progresión en el tiempo desde una primera fase de casi indiferencia y de descubrimiento de un problema del que parece no tenerse conocimiento, luego un momento de incomodidad con esta situación (a partir de mediados del siglo) y posteriormente un período de "revuelta" cuando se pasa del plano filosófico y moral al político a partir de los años $1770^{4}$ Así que podemos decir que una comedia como como L'Île des esclaves de Marivaux (2000), que fue representada por primera vez el 5 de marzo de 1725 y publicada ese mismo año (4 años después de las Lettres persanes de Montesquieu), se inscribiría plenamente en ese momento de descubrimiento de una realidad casi desconocida, y habría contribuido a sensibilizar desde las tablas a un público parisino aun poco formado en este aspecto. Un público que consume el azúcar en su mesa sin pensar en las vidas que ha costado, una sociedad consumista que, un poco como la nuestra, no quiere mirar la "trazabilidad" de los objetos que devora. Ya desde el título el dramaturgo nos hace participes de esa inquietud que le mueve al nombrar a una clase social que apenas tiene presencia. Del mismo modo que otros lo hacen en los salones, en los periódicos o en sus ensayos, Marivaux se propone desde las tablas descubrir un mundo desconocido al espectador parisino. Así pues, esta comedia es en cierto modo, el fruto de una reflexión social que favoreció el relativo progresismo del Regente, Felipe de Orleans, y que permitirá una apertura a la Razón en los primeros años de la monarquía de Luis XV.

Como sabemos Pierre Carlet de Chamblain Marivaux (París, 1688) es uno de los mayores dramaturgos del siglo XVIII, además de un excelente novelista y periodista. $\mathrm{Su}$ vida abarca tres épocas bien diferenciadas: el ocaso del reinado de Luis XIV, momento de

3 Primer texto de la literatura francesa en el que un hombre negro norteafricano toma la palabra.

4 Se suele considerar que en la primera mitad del siglo hay una fase de "indiferencia", posteriormente llega una fase de "incomodidad" (libro XV del Esprit des Lois) y finalmente una de "revuelta" cuando se pasa del plano filosófico y moral al político a partir de 1770, que culminará en el movimiento abolicionista de los 80 (Ehrard, 2008). 
austeridad y descalabro económico, la regencia de Felipe de Orleans (1715-1723) época de grandes cambios económicos, de pensamiento y costumbres, y por último el principio del reinado de Luis XV. Un factor biográfico fundamental para entender la obra que nos ocupa es su ruina económica provocada por la bancarrota de Law, y que le llevaría a tener que vivir de su pluma. Se convertiría de este modo en un autor muy prolífico y al mismo tiempo se volvió particularmente sensible a esos cambios radicales de la rueda de la fortuna, que un día nos hacen señores y al siguiente nos vuelven esclavos (Martin, 1996: 57-99). El estimulante éxito de sus obras teatrales le permitirá sobrevivir y frecuentar los grandes círculos intelectuales de la época, entrando en contacto con las nuevas ideas intelectuales y sociales, que irradiará a su público a través de sus textos como vemos en L'île des esclaves (Lagrave, 1992).

En la mayoría de sus obras aparece como tema principal el descubrimiento o la sorpresa del amor, por eso se suelen calificar de comedias sentimentales (Jutrin, 1977: 157-179). Pero como avanzaba, a menudo es un giro de la rueda de la fortuna, lo que determina la transformación de sus personajes y lo que les permite abrir los ojos. Un cambio que experimentan tanto los personajes de sus novelas, Marianne y Jacob (de La Vie de Marianne y Le paysan parvenu), como los personajes de muchas de sus comedias (Martin, 2014).

\subsection{L'île des esclaves}

Similar destino tendrán los personajes de L'Île des esclaves, dos jóvenes nobles atenienses $^{5}$ de la época clásica, Ificrates y Eufrosina, que tras un naufragio son arrojados por una tempestad marina con sus respectivos esclavos, Arlequín y Cleanta, a una isla gobernada por esclavos fugitivos. Nada más llegar deben intercambiar sus identidades con las de sus criados obligados por Trivelín, que representa el poder de la razón en la isla. En una especie de mundo al revés los amos son convertidos en esclavos y deben soportar los caprichos de sus criados, que se vengan así de sus años de esclavitud (Connon, 1993: 128-129). Los amos al ver representados sus vicios y defectos cotidianos se descubren a sí mismos en toda su crudeza. Como adelantaba para el espectador contemporáneo de Marivaux este mundo al revés no es tan lejano pues es consciente de que tras la bancarrota de Law había habido muchos señores que se habían visto reducidos a la servidumbre.

La tierra a la que han arribado esos náufragos atenienses parece estar destinada a humanizar a los antiguos señores, permitiéndoles constatar sus maldades hacia sus subordinados. Tras una serie de pruebas reaparece Trivelín, director de este juego teatral, comprobando que los nuevos amos y antiguos esclavos se apiadan de sus antiguos propietarios que se muestran incapaces e impotentes frente a la lucha por la supervivencia (Ramos Gómez, 2009: 300). Trivelín sintetiza la situación con una máxima "La diferencia de clases es tan sólo una prueba a la que nos someten los dioses.” Las dos parejas podrán entonces regresar

5 Desde la antigüedad clásica latina, Atenas es un "lugar teatral" por excelencia, ya que permite criticar las costumbres desde la distancia, como vemos por ejemplo en el teatro de Plauto (Andreau, 1968: 467). 
a Atenas, donde se espera que nadie olvide la importante lección de este naufragio de cara a un futuro mejor para todos.

\section{L'île des esclaves como retrocronotopía}

\subsection{Condiciones utópicas}

En esta comedia de un acto con 11 escenas en prosa, Marivaux reivindica el mestizaje como única solución posible para hallar la armonía entre los seres humanos por medio de una utopía social y moral. De hecho, el dramaturgo está llevando al escenario una tradición más propia de la literatura filosófica que del teatro. Marivaux se atreve de este modo en plena monarquía absoluta, sobre las tablas y ante un gran público, a llevar a cabo mediante esta utopía $^{6}$, género en cierto modo novedoso en suelo galo, reflexiones políticas y morales. Esta forma literaria que los europeos del renacimiento habían redescubierto en la obra epónima de Tomás Moro, triunfará particularmente a mediados el siglo XVIII francés, prueba irrefutable del gusto por la ilusión espaciotemporal del hombre de las Luces (Zatorska, 1992: 118-121).

Su utopía es en definitiva una recreación de las Saturnales (Saturnalia), fiestas de la Roma antigua en las que durante un breve lapso de tiempo los esclavos eran liberados de su servidumbre y cambiaban de rol con sus amos (Ibrahim 2015: 1027). La literatura de la Edad Media exploró un tópico que está asociado fuertemente con la locura: el "tópico del mundo al revés", que tiene origen en un recurso formal de la Antigüedad que consistía en la enumeración de cosas imposibles. Son propias de este tópico las imágenes que exploran la categoría de lo irracional: ciegos que conducen a ciegos, bueyes danzantes, aves que vuelan sin alas y padres de la iglesia que se encuentran en la taberna. El tópico del mundo al revés (impossibilia) ilustra unas veces el deseo y otras el temor de que las cosas cambien y se den la vuelta como un guante y pasen a ser lo contrario de lo que son. Imaginar y representar un mundo al revés, en el que los señores y esclavos han cambiado de condición es una tradición que se perpetúa en el carnaval, en la mascarada, que como sabemos entraña un movimiento crítico profundo que relativiza y vuelve laico el orden social y político (recordemos que muchos personajes de la commedia dell'arte, como Arlequín, tienen un vínculo directo con el carnaval [Moureau, 2011]). En él, como en la comedia que nos ocupa, se permite durante un tiempo limitado suprimir las restricciones establecidas por la comunidad para liberar de manera anónima las frustraciones impuestas por el orden social. De este modo Marivaux reúne la tradición popular y la intelectual para lograr difuminar la acidez de una crítica social de lo más mordaz.

6 Marivaux pone en escena otra utopía social, La Colonia, y otras dos utopías morales: La Isla de la Razón y la Disputa (Schurmans, 2004: 195-212). 


\subsection{Lo aleatorio como herramienta}

El autor, siguiendo los pasos de Plauto, va a situar su fábula utópica en una imaginaria Grecia Clásica, localización cronológica y geográfica no carente de importancia. Esto le ha de permitir abordar el tema de la esclavitud sin caer en los clichés típicos de otras obras que deseaban denunciar la terrible condición de los esclavos africanos. Por otro lado, las referencias a la esclavitud en un país cuya economía se basaba como decíamos en el comercio triangular, debían de causar un gran impacto en unos espectadores aún poco acostumbrados a reflexionar al respecto. $\mathrm{Y}$ al mismo tiempo, expresando su fuerte resentimiento social contra sus amos, Arlequín y Cleanta, se convierten en portavoces de todos aquellos a los que la sociedad de las nacientes luces negaba la palabra (Moraud, 1981).

Por otra parte, recurriendo a personajes europeos, la obra nos muestra que el esclavo puede ser cualquiera. Este en cierto modo era un miedo real en la Edad Moderna y de hecho lo encontramos a menudo en la literatura (como en las Fourberies de Scapin de Molière), y es que desde tiempos inmemoriales los árabes tenían esclavos cristianos. Aunque la esclavitud de los blancos fuera relativamente reducida en comparación con la de los negros en América, las cifras fueron considerables (una media de 35.000 cautivos al año [Davis, 2006]), y se prolongó hasta el siglo XIX y el apogeo del colonialismo francés. Algunos autores llegan a asegurar que los críticos abolicionistas se inspiraron en este drama.

\subsection{La isla}

Geográficamente, esa isla donde rigen naturaleza y razón y en la que va a transcurrir la obra, es una mezcla de la Citerea galante de Watteau y de la del modelo inglés de Robinson Crusoe de Defoe (1719) con quien también comparte el tema del naufragio. Es un espacio mítico elegido porque sugiere al espectador del XVIII un lugar de ruptura simbólica con la civilización donde se supone en consecuencia que todo se estructura bajo un nuevo sistema de funcionamiento social. Ilustra un lugar utópico que entraña una separación evidente del mundo de los espectadores. Representa una especie de laboratorio ideal que permite probar nuevas formas de relacionarse, un hospital para tratar los vínculos entre los hombres. Pero un lugar donde, tampoco lo podemos olvidar, después de ofrecerse múltiples posibilidades, todo vuelve a su estatus quo inicial tras ese sueño de libertad, ya que la utopía desde el momento en que es escenificada se ve limitada a una duración: lo único que se busca es una conversión moral de los individuos. Sin embargo, aunque el regreso a la normalidad sea inevitable, los personajes y con ellos el público ya han entrevisto en este islote la posibilidad de ser libres. Y como sabemos, todas estas escenas premonitorias acabarán por tornarse realidad en la Revolución.

Para los espectadores de las Luces, la isla también implica, por sus connotaciones 
geográficas de lejanía y exotismo, un vínculo evidente con las nacientes colonias donde imperaba la esclavitud (frente a la metrópoli donde, no podía emplearse mano de obra esclava desde la prohibición de la misma por la reina Bathilde [630-680], a su vez antigua esclava así como por el edicto de 1315 de Luis X el Obstinado [1289-1316] $]^{7}$ ). Unas colonias cercanas y lejanas, con unas leyes particulares y con un funcionamiento social aparentemente similar pero muy diferente en el fondo. ¿Hay algo de esas islas de América en el texto de Marivaux? Se podría aventurar una hipótesis más que plausible al respecto: frente a la escuela de pensamiento que aseguraba que los negros de las plantaciones eran muy felices, porque no se sublevaban (algo que en algunas universidades americanas se ha defendido hasta 1998 ${ }^{8}$ ), Marivaux se atreve a defender lo contrario. Escenifica a unos esclavos que huyen de sus condiciones de vida insoportables refugiándose en una isla, poniendo en peligro su vida para llegar a ese lugar remoto. Esto era algo que se había producido en noviembre de 1639, en la isla caribeña de San Cristóbal (Saint Kitts), que entonces se hallaba bajo dominio francés, cuando una centena de esclavos habían huido a la parte alta de la isla (Mont Misery) y habían creado un poblado, únicamente accesible a través de un escarpado desfiladero. Desde allí lanzaban ataques a las plantaciones vecinas para liberar esclavos y atacar a los amos. Pese a todo, pasado el tiempo se consiguió reducirles y destruir el poblado con una armada de más de quinientos hombres dirigidos por Philippe de Longvilliers de Poincy. No obstante, el jefe de los amotinados consiguió huir y evitar a los militares más de tres años antes de ser capturado. Sobre él corrían múltiples rumores, como que tenía poderes mágicos (algo que no deja de hacernos pensar en el Trivelín marivaldiano). Finalmente, se le capturó y se le evisceró en la plaza pública para que sirviera de lección a todos los demás esclavos. Desde el comienzo de comercio de esclavos transatlántico existen otras historias de fugitivos en tierras mexicanas y brasileñas, pero ninguna tan similar a la de nuestra comedia, ni tampoco en suelo colonizado por franceses. Por otro lado, resulta interesante subrayar que los libros de historia han sido concienzudamente expurgados de cualquier referencia a este tipo de levantamientos para reforzar la teoría de una esclavitud dichosa y civilizadora.

\subsection{La máscara arcaica}

La localización cronológica en la Antigüedad permite al autor remontarse a los albores de la civilización. Marivaux busca alejarse simbólicamente del presente, pero también desenraizar la esclavitud desde su origen. Si, como adelantaba anteriormente, los autores clásicos no idearon un mundo utópico sin esclavitud, Marivaux se atreve a recrearlo en esta retrocronotopía (Negrel, 2003: 320-324). Se retrotrae a la antigüedad y fija en el tiempo su

$7 \quad$ El 3 de julio de 1315, un edicto del rey Luis X, el Obstinado, abolió la esclavitud en el reino de Francia. Cualquier esclavo que pusiera en él sus pies era declarado libre.

8 Hasta 1998, la universidad de Chapel Hill en Carolina del Norte en Estados Unidos, proponía un curso donde se enseñaba esta teoría. 
ideal. Además, paradójicamente esto "tranquiliza" al espectador que conoce el "futuro" de ese pasado, o al menos cree conocerlo...

Por otra parte, Marivaux con la máscara del mito arcaico, se permite identificar esclavitud y servidumbre, algo que había de impactar a sus receptores que podían sentir amenazados sus privilegios. El tema se muestra como vemos políticamente incorrecto para la época, ya que, mediante la caricatura, juegos muy delicados y en un ambiente casi onírico anticipa escritos teatrales y no teatrales de la segunda mitad del siglo, resultando un gran transgresor de costumbres y estereotipos (Vázquez, 2008). No resulta extraño por lo tanto saber que Beaumarchais apreciaba esta comedia considerablemente y la consideraba un "petit bijou", una "joyita". No obstante, no debemos olvidar que, pese a lo novedoso del tema y de sus personajes, la obra no supone una tentativa revolucionaria ni supone un cuestionamiento explícito del orden establecido: únicamente es una invitación a la reflexión por medio de una visión de la relatividad de nuestra condición, como sucede a menudo con las obras de las Luces.

En el fondo los principios como la fraternidad, el perdón o el sometimiento a la Providencia enarbolados por el dramaturgo en esta pieza, tienen un fundamento de inspiración esencialmente cristiana, algo que desde luego le aleja claramente de las futuras posiciones de un Voltaire o un Beaumarchais (Coulet \& Gilot, 1973). Pero estas resonancias religiosas parecen un cuestionamiento de los principios de esos sabios y teólogos católicos franceses como Bossuet, Jean Pontas, Germain Fromageau o Bellon de Saint-Quentin, que en sus textos sobre la esclavitud nunca la cuestionaron ni la condenaron ${ }^{9}$. Para ellos era una institución de derecho bélico incluida en el derecho romano y admitida por el derecho canónico, por el Antiguo y el Nuevo Testamento, así como por los Padres de la Iglesia (Quenum, 2008). Bossuet escribía en su artículo 50 de su Cinquième Avertissement aux protestants en 1689-1691: “Condamner l'esclavage reviendrait à condamner le Saint-Esprit qui ordonne aux esclaves, par la bouche de Saint-Paul, de demeurer en leur état et n'oblige pas le maître à les affranchir" (Bossuet, 1863: 468). De hecho, es fundamental poner de relieve que hasta Henry Grégoire (1750-1831), el abate revolucionario, no se encuentra un defensor real de la causa antiesclavista en el seno de la iglesia romana.

\section{Conclusiones ¿un Marivaux revolucionario?}

\subsection{Por el estilo a la esencia}

En lo relativo a la temática, tal y como apuntábamos al desarrollar la trama, nos hallamos ante un triunfo absoluto de la estética de la condensación: Marivaux recurre a unos pocos personajes, a un lapso de tiempo considerablemente breve y a una intriga de lo más minimalista consiguiendo de este modo que el espectador se focalice en lo esencial: los

9 En las iglesias reformadas inglesas y americanas existen voces discrepantes al respecto. 
cambios que se operan en los hombres motivados por los cambios del destino. Frente a otras comedias de vertiente más sentimental, en esta pieza el dramaturgo mezcla lo cómico y lo patético, mostrando un contenido de índole claramente social, ya que aborda la alienación social y la exclusión. En una isla utópica, metáfora de la sociedad del siglo XVIII, se juzgan las relaciones amo-esclavo y señor-criado, oponiendo la ociosidad no productiva a la esclavitud generadora de riqueza, choque que degenera en la ausencia de una mínima conciencia de humanidad de cara a los supuestos inferiores (Rigault, 1969). Marivaux, un burgués ennoblecido se atreve a discutir los privilegios de la nobleza de espada, para promover un nuevo orden fundamentado en la utilidad social, el respeto y la generosidad.

\subsection{Contra la aristocracia fútil y misógina}

El autor condena a los aristócratas por su frivolidad, su existencia fútil, derrochadora e improductiva, su parasitismo y su inutilidad social: su única ocupación es jugar a seducirse en los salones. Unos hábitos que la obra va a diseccionar con crudeza en la boca de los criados. Uno de los principales rasgos atacados será el orgullo. Este rasgo, propio en particular de la nobleza de espada, más que de la de toga (de la que el autor se siente más cercano), se materializa en su arrogancia y desprecio hacia los esclavos, pero también en forma de cólera que se materializa incluso en castigos corporales (que no dejan de evocar los de ciertos personajes del marqués de Sade). Su suficiencia la marcan a nivel estilístico en la obra por su empleo del "tu" con los subordinados (frente a Trivelín que, respetuoso con todos, les tratará a todos por igual de "vous") y por su negación de la existencia del otro por medio de la negación del patronímico, lo que convierte a los esclavos en propiedad de sus amos, que les llaman por apodos, como a un animal doméstico, o simplemente diciéndoles "Eh toi!". De este modo el esclavo parece necesitar a su señor para existir. Pero al mismo tiempo, en la obra, se plantea una cuestión esencial en la boca de Cleante: ¿pueden los señores existir sin los esclavos? La respuesta resulta evidente, ya que sin siervos no hay amos.

Y por último el autor denuncia en los señores el abuso masculino de fuerza que, en esta inversión de papeles, se vuelve aún más flagrante. Durante los galanteos que se producen tras el cambio de papeles salta a la vista una problemática evidente: el señor podría permitirse entablar amores ancilares con una criada porque supuestamente eso la "revalorizaría" a ella, pero la señora nunca puede permitirse (ni siquiera tras el cambio de roles) un amor con un criado (Nakayama, 2002). Si en este caso el criado abusa de su nueva condición, los espectadores viven esa relación como una violación, lo que les hace comprender mejor la realidad de la situación inversa, que en realidad es su vida cotidiana. A este respecto podemos añadir que la violación de esclavas por europeos era un fenómeno tan extendido, que el pintor flamenco Christian van Couwenbergh (1604-1667) lo recogió en un cuadro de 1632 titulado "El rapto de la negra" o "La violación de la negra" que hoy se conserva en el museo de 
Estrasburgo. En él encontramos a dos jóvenes europeos desnudos, dispuestos a violar a una mujer africana. Uno de ellos la señala burlándose de sus lamentaciones mientras el otro la retiene. Un tercer personaje masculino, que permanece vestido, parece mostrar una profunda reprobación que evidentemente comparte con el pintor que con su obra denuncia crudamente aquella práctica habitual de África, de las colonias y de buena parte de Europa.

\subsection{Marivaux trasformando desde las tablas}

Evidentemente pese al minimalismo de la obra, Marivaux no nos presenta únicamente los defectos de los amos sino también los de los criados que son los atribuidos de manera tradicional a los esclavos del teatro clásico latino; por ejemplo, Cleanta es parlanchina y Arlequín bebe más de lo razonable. Arlequín además conserva los rasgos típicos de este personaje de los orígenes de la commedia dell'arte: su apariencia de mendigo buscaba afianzar su estatus de esclavo y su máscara de cuero negro y de aspecto casi animal reforzaban dicha imagen (Ibeas-Altamira, 2017: 8-10). De este modo y con sus juegos de palabras, sus burlas y su gestualidad cómica los criados desencadenarán la risa que permitirá una desdramatización de la situación y al mismo tiempo una imprescindible toma de conciencia. Porque en el fondo son de una gran nobleza y de una sincera emotividad como demuestra el final de la pieza, en el que perdonan a sus amos sin dudar. De este modo los esclavos de Marivaux rompen con la ideología racista que atribuye a los seres humanos rasgos de carácter y de calidad moral inferiores a sus atributos reales. Con su inocencia casi infantil nos llegan incluso a evocar el mito del "buen salvaje". Humor, sentimientos y por encima de toda razón permitirán que se opere la imprescindible catarsis.

No resulta extraño por lo tanto que esta comedia haya interesado particularmente a los directores en los últimos años incluso más allá de las fronteras galas (y podemos poner en relieve en particular la puesta en escena española de Juli Leal con su Utopía Marivaux [Leal, 2007] o la traducción de 'La isla de los esclavos' y 'La colonia' por parte de Lydia Vázquez [Marivaux, 2014]) por su fusión explícita del teatro filosófico y social que le inscribe de lleno en la corriente de crítica social "prerrevolucionaria" y "preantiesclavista".

\subsection{La revolución marivaldiana hoy}

Retomando las representaciones de la esclavitud desde el teatro clásico e integrando los debates de su época sobre la cuestión, Marivaux dibuja un marco ideal para que su espectador reaccione ante una realidad que le resulta casi invisible. Por su interés en las cuestiones sociales, morales y políticas, el dramaturgo toma parte activa, como podemos comprobar, en el siglo de los filósofos y lo hace por medio de una utopía. Como la isla que dibuja, su pieza teatral es un lugar de observación donde el espectador guiado por el señor 
del lugar, Trivelín, puede analizar y "reparar" sus relaciones con el prójimo y con la sociedad. Por ello se trata de una cronotopía social y moral, porque en una tierra ignota regida por unas leyes particulares sus múltiples personajes, representantes de los espectadores de las Luces, pero perfectamente intercambiables por los del presente, deben confrontarse no solo al proyecto colectivo que se les impone, sino que también deben desarrollar sus propias realizaciones personales. Si Marivaux limita el alcance de su sueño utópico, y con su regreso al orden establecido, con su "entierro de la sardina", parece limitarse a corregir la situación original, no debemos olvidar que el viaje a Utopía es, se quiera o no, de no-retorno. Las fantasías sociales son, al fin y al cabo, un avance de lo posible, si bien puede incomodar al receptor. Las reflexiones sobre las condiciones del esclavo, aunque no se asuman e interioricen en un primer momento, quedan ahí, y ya han sido planteadas. Y el espectador ha entendido que cualquiera puede verse en dicha situación, ni siquiera el género es una barrera. El público del siglo XVIII, como el del XXI, no puede quedar impávido, ni pretender conservar la inocencia.

El moralista Trivelín nos hace cuestionarnos si somos dignos de la situación en la que nos hallamos e incluso si tendríamos un comportamiento mejor si tuviéramos otra condición: ¿Si estuviéramos en el siglo XVIII actuaríamos de otra manera? Este maestro de ceremonias, alter ego del autor, es a la vez un experimentador, un pedagogo, un analista, un terapeuta y un juez que trata y asiste a los personajes y a nosotros espectadores, que debemos abrir los ojos a un mundo nuevo. ¿Acaso en nuestro deslumbrante siglo XXI la esclavitud está realmente erradicada? El azúcar que consumo, la ropa que llevo, el ordenador que utilizo ¿están manchados de sangre? Como un dios todopoderoso y sabio Trivelín nos conduce por su isla, por su obra teatral, para hacernos cambiar, y permitirnos salir de la sala con una mirada nueva sobre un mundo que creíamos conocer y que sin embargo es muy diferente.

\section{Referencias bibliográficas}

AndreAu, Jean. 1968. "Banque grecque et banque romaine dans le théâtre de Plaute et de Térence" in Mélanges de l'école française de Rome, $\mathrm{n}^{\circ}$ 80-2, 461-526.

Bossuet, Jacques-Bénigne. 1863. Euvres complètes, t. XV. París, Éditions Lachat, Louis Vivès.

CAlvert, Brian. 1987. "Slavery in Plato's Republic" in The Classical Quarterly New Series, vol. $37, \mathrm{n}^{\mathrm{o}} 2,367-372$.

Chesnais, Robert (introduction et notes). 2000. Le Code Noir. Paris, Ed. L'Esprit frappeur.

Connon, Derek. 1993. "The Servant as Master: Disguise, Role-Reversal and Social Comment in Three Plays of Marivaux" in GEORGE, David \& GOSSIP, Christopher (eds.). Studies in the Commedia dell'Arte. Cardiff, U. of Wales, 128-129. 
Anales de Filología Francesa, n. ${ }^{\circ}$ 27, 2019

Juan Manuel Ibeas-Altamira

Coulet, Henri y Gilot, Michel. 1973. Marivaux. Un humanisme expérimental. Paris, Larousse.

Davis, Robert C. 2006. Esclaves chrétiens, maîtres musulmans. L'esclavage blanc en Méditerranée (1500-1800). Cahors, Éditions Jacqueline Chambon.

EHRARD, Jean. 2008. Lumière et esclavage. L'esclavage colonial et l'opinion publique en France au XVIIIème siècle. Paris, André Versailles Editeur.

Garnsey, Peter. 1996. Ideas of slavery from Aristotle to Augustine. Cambridge, University Press.

Ibeas-Altamira, Juan Manuel. 2017. "Del animal al personaje mítico sobre las tablas: de la Commedia dell'arte a Marivaux" in Degrés. Revue de synthèse à orientation sémiologique, $\mathrm{n}^{\mathrm{o}}$ 201-169-170, 8-15.

Ibrahim, Laïth. 2015. “L'espace utopique dans le théâtre de Marivaux (L'Île des Esclaves, L'Île de la Raison, La Colonie)" in Dirasat, Human and Social Sciences, vol. 42, n 3, 1027 1039.

JAUCOURT, Louis de. 1751-1772. “Traite des nègres” in DIDEROT, Denis \& D'ALEMBERT, Jean (éd.). Encyclopédie ou Dictionnaire des sciences, des arts et des métiers. Paris, Briasson.

Jutrin, Monique. 1977. "Le théâtre de Marivaux, une 'phénoménologie' du cœur ?" in Dix-Huitième siècle, $\mathrm{n}^{\mathrm{o}}$ 7, 157-179.

KLefF, Patrice. 2006. C'est-à- ce prix que vous mangez du sucre. Les discours sur l'esclavage d'Aristote à Césaire. Paris, Flammarion.

Lagrave, Henri. 1992. Marivaux et sa fortune littéraire. Saint-Médard-en-Jalles, Ducros.

Lalande, Jacques. 1962. Vocabulaire technique et critique de la Philosophie. Paris, Presses Universitaires de France.

Leal, Juli. 2007. Utopía Marivaux. Valencia, Teatres de la Generalitat Valenciana,

Marivaux, Pierre de. 2000. Théâtre Complet, ed. F. Deloffre y F. Rubellin. Paris, La Pochotèque/Classiques Garnier.

Marivaux, Pierre de. 2014. 'La isla de los esclavos', y 'La colonia' (Introducción de Lydia Vázquez y Juli Leal). Madrid, ADE.

Martin, Christophe. 1996. "Le jeu du don et de l'échange. Économie et narcissisme dans $L a$ Double Inconstance de Marivaux" in Littératures, no 35, 57-99.

Martin, Christophe. 2014. Mémoires d'une inconnue: Étude de La Vie de Marianne de Marivaux. Publications de l'Université de Rouen et du Havre,

Moraud, Yves. 1981. La Conquête de la liberté de Scapin à Figaro. Paris, PUF.

Moureau, François. 2011. Le goût italien dans la France rocaille. Paris, Presses Universitaires de Paris-Sorbonne. 
Nakayama, Tomoko. 2002. Le théâtre de Marivaux et le travestissement. Études de Langue et Littérature Françaises de l'Université de Hiroshima.

Negrel, Eric. 2003. "Marivaux utopiste. Du monde renversé à la rhétorique des passions" in SALAÜN Franck (dir.). Marivaux subversif? Paris, Desjonquères, 320-335.

Nelly, Schmidt. 2008. L'abolition de l'esclavage: 5 siècles de combats (XVIème/XXème siècles). Paris, Fayard,

Pellegrin, P. 1982. “La théorie aristotélicienne de l'esclavage : tendances actuelles de l'interprétation" in Revue philosophique de la France et de l'étranger, t. 172, n 2, 345-357.

Quenum, Alphonse. 2008. Les Églises chrétiennes et la traite atlantique du XVe au XIXe siècle. París, Karthala.

Ramos Gómez, María Teresa. 2009. "La Fausse Suivante, ou la dynamique du triangle” in Çédille, revista de estudios franceses, $\mathrm{n}^{\circ} 5,283-303$.

Rigault, Claude. 1969. Les Domestiques dans le théâtre de Marivaux. U. de Sherbrooke.

Schurmans, Fabrice. 2004, "Le Tremblement des codes dans les trois Iles de Marivaux" in Revue d'Histoire du Théâtre, $\mathrm{n}^{\circ} 3$ (223), 195-212.

Vazquez, Lydia (dir.). 2008. "Marivaux, moderne et libertin”, Revue des Sciences Humaines, $\mathrm{n}^{\circ} 291$.

Verlinden, Charles. 1955. L'esclavage dans l'Europe médiévale. Publications de la Faculté des Lettres de l'Université de Gand.

Vlastos, Gregory. 1968. “Does Slavery Exist in Plato's Republic?” in Classical Philology, $n^{\circ} 63 / 4,291-295$.

Wallon, Henri. 1988. Histoire de l'esclavage dans l'Antiquité. Paris, Robert Laffont.

ZATORSKA, Zabella. 1992. "L'Ile des esclaves de Marivaux: une utopie à l'italienne" in MATuCcI, Mario (ed.). Marivaux e il teatro italiano. Pise, Pacini, 118-121. 